\title{
SIMULATION OF DYNAMIC CHARACTERISTICS OF GaN $p$ - $i-n$ AVALANCHE DIODE OPERATING AS PARTICLE DETECTOR WITH INTERNAL GAIN
}

\author{
J. Vyšniauskas ${ }^{a}$ and E. Gaubas ${ }^{b}$ \\ a Institute of Applied Electrodynamics and Telecommunications, Vilnius University, Sauletekio 3, 10257 Vilnius, Lithuania \\ ${ }^{\mathrm{b}}$ Institute of Photonics and Nanotechnology, Vilnius University, Sauletekio 3, 10257 Vilnius, Lithuania \\ Email: juozas.vysniauskas@ff.vu.lt; eugenijus.gaubas@ff.vu.lt
}

Received 8 December 2017; revised 15 January 2018; accepted 21 June 2018

\begin{abstract}
An evolution of the transient characteristics of the GaN $p-i-n$ diodes, operating in the avalanche mode and acting as particle sensors, has been simulated by using the Synopsys TCAD Sentaurus software package and the drift-diffusion approach. Profiling of the charge generation, recombination and drift-diffusion processes has been performed over a nanosecond time-scale with a precision of a few picoseconds and emulated through the photo-excitation of an excess carrier domain at different locations of the active volume of a diode. Shockley-Read-Hall (SRH), Auger and radiative recombination processes have been taken into account. Fast and slow components within a current transient have been analysed based on the consideration of the carrier spatial distribution at different instants of the avalanche process. The internal gain due to charge multiplication ensures the sufficient charge collection on electrodes of the relatively thin $(5 \mu \mathrm{m})$ diode operating in the avalanche mode. It has been shown that the simulated evolution of the detector transient responses by employing the drift-diffusion approach reproduces properly the qualitative modifications of the main features of a detector with an internal gain, realized by induction of the avalanche processes governed by the applied external voltage.
\end{abstract}

Keywords: GaN, simulation, $p$ - $i-n$ diodes, impact ionization, particle detectors, TCAD

PACS: $85.30 . \mathrm{Mn}$

\section{Introduction}

Recent advances in semiconductor technology are attained due to intensive investigations and wide applications of gallium nitride $(\mathrm{GaN})$ based semiconductor devices, such as light emitting diodes [1, 2] and lasers [3, 4], photodiodes [5, 6], HEMTs [], 8], surface acoustic wave sensors [9] and acousto-optic devices [10, 11]. Gallium nitride is one of the most promising materials for fabrication of particle detectors operating within a harsh radiation environment [12-18], based on small dark as well as leakage currents and high breakdown voltages. The excess carrier pair generation by high energy protons comprises $40-80$ pairs per a $\mu \mathrm{m}$ length of the device active region per proton [19, 20]. Thus, to get the measurable signals and to detect particles with a rather small interaction cross-section, relatively thick $(300-500 \mu \mathrm{m})$ devices are needed [17]. The GaN crystalline material of a proper quality is usually obtained by the MOCVD technique. However, the MOCVD grown epilayers are rather thin $(2-12 \mu \mathrm{m})$. The inevitable noise level in the measurement circuit is usually equivalent to $3 \cdot 10^{4}$ electron-hole pairs, close to a minimal impact particle (MIP). To get a measurable signal in a $2-12 \mu \mathrm{m}$ thick detector, the internal amplification is needed. This can be 
implemented by using carrier impact ionization processes. Such a particle detector resembles the avalanche photodiode (APD) fabricated on $\mathrm{GaN}[5,6,21-23]$, with an active region covering several micrometres. To predict characteristics of a thin detector with an internal gain, a detection process can be emulated by considering a drift of excess carriers leading to the avalanche processes in the active region of a diode. A set of the most important characteristics of APD consists of dark current, photocurrent, gain, spectral response, excess noise, etc. Majority of papers devoted to APD are addressing the analysis of these characteristics. However, dynamic characteristics of APD [24-32, especially based on GaN, are less examined. A pulsed response of APD shows [25, 27, 29] that the rise-time of the APD current is rather short, while the fall-time is longer by several orders of time-scales. This is a crucial disadvantage of APDs for high speed applications. However, it may be an advantage for particle detectors allowing an increased charge collection on electrodes.

This work is addressing the simulation of the dynamic characteristics and avalanche processes in the $p-i-n$ structure wurtzite-phase $\mathrm{GaN}$ diode operating as a radiation detector with an internal gain. The detector current transients have been simulated by the technology of computer aided design (TCAD) and their dependences on the applied DC voltage, carrier lifetime and location of radiation beam incidence within a layer of intrinsic conductivity have been analysed.

\section{A simulation model and parameters}

It has been assumed that a detector consists of $1 \mu \mathrm{m}$ thickness $\mathrm{N}^{++}$and $\mathrm{P}^{++}$regions with a large doping density of $10^{19} \mathrm{~cm}^{-3}$ at the contacts and an undoped intrinsic region (5 $\mu \mathrm{m}$-thick layer). Donor and acceptor distribution is approximated by a complementary error-function $\operatorname{erfc}(x)$ with the assumed diffusion length of $0.01 \mu \mathrm{m}$. The diode area is assumed to be $S=7.85 \cdot 10^{-5} \mathrm{~cm}^{2}$. Detector current transients have been simulated by considering a photo-excitation of the excess carrier domain which appears at different locations $x_{0}$ within the active volume of a sensor, ascribed to various radiation beam incidence positions. As an initial condition, it has been assumed that this carrier domain occupies $0.1 \mu \mathrm{m}$ in space and
2 ps in time. To avoid the feedback effects, simulations were mainly performed for the position $x_{0}=4.2 \mu \mathrm{m}$ (within an inter-electrode distance) of excess carrier pair injection. For this initial injection position, the bipolar drift occurs where the electron and hole packets reach synchronously the corresponding $\mathrm{N}^{++}$(positively charged) and $\mathrm{P}^{++}$(negatively charged) electrode regions. The parameters of the optical excitation wavelength of $\lambda=0.47 \mu \mathrm{m}$ and its power density $10^{4} \mathrm{~W} / \mathrm{cm}^{2}$ were chosen in simulations. In experiments, the mentioned parameters might be reached with a sharply focused laser beam.

The $p$ - $i$ - $n$ structure diode has been analysed using a drift-diffusion model [33], based on the solution of the Poisson's equation for electrostatic potential and continuity equations for electrons and holes, installed within the Synopsys TCAD Sentaurus platform. This model is adequate to the considered diode structure with a total interelectrode length of $7 \mu \mathrm{m}$ and ignores any "dead space" effects essential for submicron devices. All the material parameters taken for simulations correspond to the lattice temperature of $T=300 \mathrm{~K}$. Values of the parameters (such as Shockley-ReadHall (SRH) recombination lifetimes for electrons and holes, dependent on doping and excitation densities, of the coefficients of band-to-band $\mathrm{Au}$ ger recombination, coefficient of the radiative recombination and coefficients of the charge generation due to impact ionization, - those are installed within Synopsys TCAD platform) were chosen to be adequate to a wurtzite-GaN. Actually, the electron and hole SRH lifetime of 1 ns corresponds to the Synopsys TCAD standard parameter file for GaN. Values of the impact-ionization coefficients $\left(\alpha_{n}\right.$ and $\alpha_{p}$ for electrons and holes, respectively) were calculated using the Van Overstraeten and de Man model [34] based on the Chynoweth law as

$$
\alpha_{n, p}(E)=a_{n, p} \exp \left(-\frac{|E|}{b_{n, p}}\right) .
$$

Here $E$ is the electric field strength, while other parameters are as follows: $a_{n}=2.9 \cdot 10^{8} \mathrm{~cm}^{-1}$ and $b_{n}=3.4 \cdot 10^{7} \mathrm{~V} / \mathrm{cm}$ for electrons, $a_{p}=5.41 \cdot 10^{6} \mathrm{~cm}^{-1}$ and $b_{p}=1.96 \cdot 10^{7} \mathrm{~V} / \mathrm{cm}$ for holes, respectively.

Values of carrier mobility dependent on the mechanisms of scattering by phonons, ionized impurities and inter-valley scattering have been 
calculated using the well-known models, developed for different scattering processes. Values of the weak field mobility $\mu_{n}=1500 \mathrm{~cm}^{2} / \mathrm{Vs}$ and $\mu_{p}=100 \mathrm{~cm}^{2} / \mathrm{Vs}$ for electrons and holes in the un-doped $\mathrm{GaN}$ material, respectively, ascribed to the phonon scattering, were employed in simulations. Also, the effect of velocity saturation in strong electric field has been taken into account using values of the saturation velocity of $v_{n s}=1.8 \cdot 10^{7} \mathrm{~cm} / \mathrm{s}$ and $v_{p s}=10^{7} \mathrm{~cm} / \mathrm{s}$ for electrons and holes, respectively. The dependence of carrier drift velocity on the electric field was calculated using the formula based on precise Monte Carlo calculations performed in [35]:

$$
v_{n, p}=\frac{\mu_{n, p}|E|+v_{n s, p s}\left(\frac{|E|}{E_{1 n, p}}\right)^{\beta_{n, p}}}{1+\gamma_{n, p}\left(\frac{|E|}{E_{1 n, p}}\right)^{\delta_{n, p}}+\left(\frac{|E|}{E_{1 n, p}}\right)^{\beta_{n, p}}} .
$$

Here such values were assumed: $E_{1 n}=$ $2.2089 \cdot 10^{5} \mathrm{~V} / \mathrm{cm}, E_{1 p}=4 \cdot 10^{3} \mathrm{~V} / \mathrm{cm}, \beta_{n}=7.2044$, $\beta_{p}=4, \delta_{n}=0.7857, \delta_{p}=0, \gamma_{n}=6.1973, \gamma_{p}=0$. The dependence of the carrier diffusion coefficient on the electric field was calculated using the mobility values and the Einstein relation.

Most of the simulations were performed assuming only a constant (DC) voltage source connected in series with a diode. For comparison, a few simulations have been made using a simple circuit consisting of a constant voltage source connected in series with the diode and a load resistance of $R_{\mathrm{L}}=50 \Omega$.

\section{Simulation results and discussion}

\subsection{Profiling of excess carrier density and generation rates}

Profiling of the excess carrier domain injection as well as its separation to electron and hole packets, and the changes of the vertex position of the packets have been performed at different instants during the formation of a transient, and the simulated profiles are depicted in Fig. 1. Also, the outspread of the packets appears due to the carrier diffusion processes, as illustrated in Fig. 1.

Just after the optical pulse ends, the rectangular electron and hole packets make the $0.1 \mu \mathrm{m}$ width sheets with the sharp carrier density gradients. After a rather short time (at $t=4 \mathrm{ps}$ ), the electron and hole packet shapes approach the Gaussian one, due to carrier diffusion, which also leads to a broadening of the carrier packets. The electron diffusion coefficient is larger than that of the holes, therefore the electron packet at $t=4$ ps becomes wider by a factor of 1.5 than that of the hole sheet. Consequently, the density of the carriers decreases within a packet vertex if a sheet area is invariant due to a negligible recombination. Simultaneously, the carrier drift leads to spatial shifts of the vertexes of electron and hole packets.

For the strongest electric fields (of $E=2.65 \cdot 10^{6}$ $\mathrm{V} / \mathrm{cm}$ ), electrons and holes drift in opposite directions, by acquiring the saturation velocities. There, an intensive impact ionization takes place together with carrier drift and diffusion. The spatial distribution

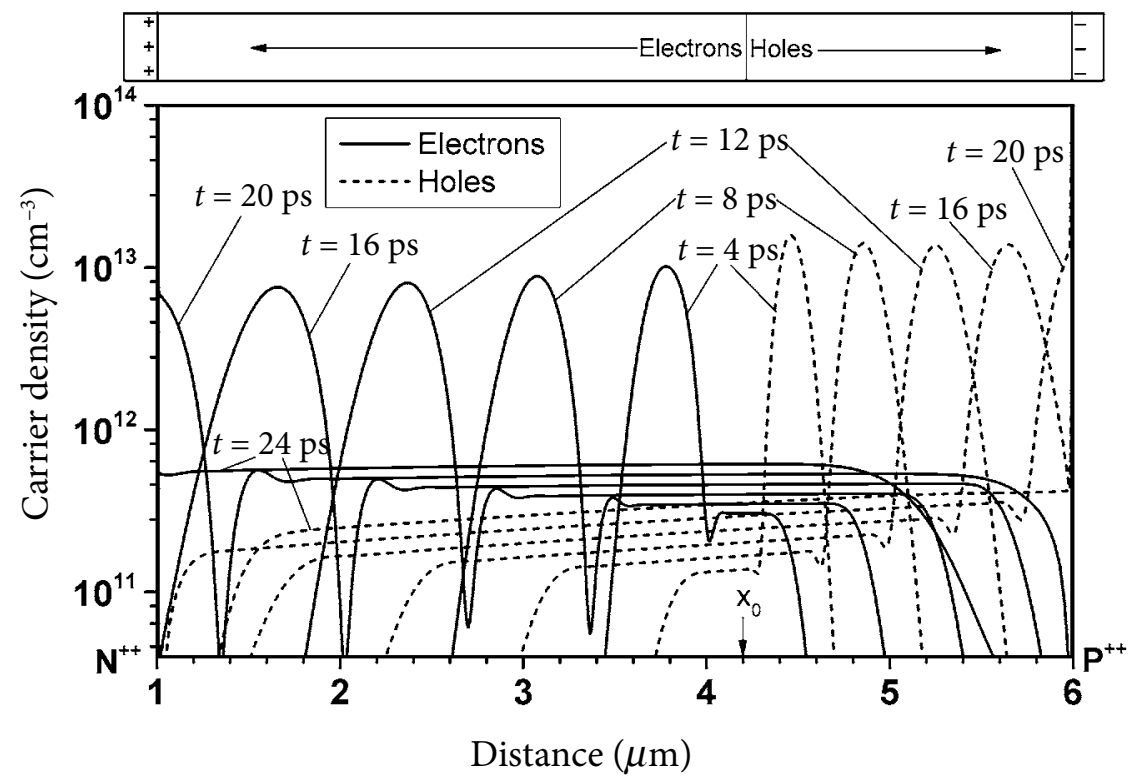

Fig. 1. Profiles of the primary excess carrier distribution within a drift layer at various instants during the carrier drift from the initial $x_{0}=4.2 \mu \mathrm{m}$ domain position to the $\mathrm{N}^{++}$(at the $1 \mathrm{st} \mu \mathrm{m}$, for electrons) and $\mathrm{P}^{++}$(at the 6th $\mu \mathrm{m}$ within the inter-electrode space, for holes) regions nearby metallic electrodes. 
of the impact generation rate $\left(G=\alpha_{n} n v_{n s}+\alpha_{p} p v_{p s}\right)$ (Fig. 2) imitates the carrier distribution profiles obtained for rather strong external fields (Fig. 2). The value of the hole ionization coefficient $\left(3.44 \cdot 10^{3} \mathrm{~cm}^{-1}\right)$ is larger by a factor of 4 than that $\left(8.26 \cdot 10^{2} \mathrm{~cm}^{-1}\right)$ for electrons. However, the values of the saturation velocity for holes are less by a factor of 1.8 than those for electrons. As a result, the carrier density within the vertex of the hole packet is higher by a factor of 1.7 than that within the vertex of the electron sheet, due to the slower diffusion of holes (Fig. 1). Consequently, the hole impact ionization rate at the vertex of the hole packet is 4 times higher than that for the electron packet (Fig. 2).

The SRH recombination rate is lower (by 3 orders of magnitude) than the impact generation rate (Fig. 22). At an instant of $t=10 \mathrm{ps}$, the carrier generation rate within the vertex of the electron packet reaches a value of $1.2 \cdot 10^{23} \mathrm{~cm}^{-3} / \mathrm{s}$ (Fig. 2). During a time-interval of $1 \mathrm{ps}$, the electron packet vertex shifts by a distance of $0.18 \mu \mathrm{m}$ and generates the electron-hole pairs of $1.2 \cdot 10^{11} \mathrm{~cm}^{-3}$ density. This carrier density is considerably lower than the electron density at the vertex of the packet $\left(8 \cdot 10^{12} \mathrm{~cm}^{-3}\right)$. The secondary carrier density, generated by the impact-ionization within the hole packet, approaches a value of $4 \cdot 10^{11} \mathrm{~cm}^{-3}$, and it is considerably lower than the hole density $\left(1.5 \cdot 10^{13} \mathrm{~cm}^{-3}\right)$ at the vertex of the hole packet. Despite the fact that the secondary carrier domain, generated by the impact-ionization segment at a time moment of $t=10 \mathrm{ps}$, covers a spatial seg- ment that is six times wider than the primary carrier packets, the convectional current density of a diode is mainly determined by the primary carriers. At an instant of $t=20 \mathrm{ps}$, just before the carrier packets enter the high doping, near-electrode regions, the convectional current densities ascribed to the primary and secondary carriers are approximately equal (Fig. 3).

Carrier velocity changes follow the electric field variations in time, according to the assumptions of the drift-diffusion model, where no delay and feedback effects are considered. Thereby, the secondary electrons within the packet of primary electrons drift synchronously with the primary ones, having a saturation velocity, until these carriers reach the $\mathrm{N}^{++}$region. The secondary holes (of the impact ionization generated carrier pairs) drift in the opposite direction and leave quickly the primary electron packet. Due to a big difference between densities of the primary and secondary carriers, a contribution of the secondary carriers to the total density of carriers within the packets of holes and electrons is small, thus, not observable in Fig. 1. However, the clearly observable "tail" components of the secondary holes generated by electrons on the right of the electron packet and the secondary electrons generated by holes on the left of the hole packet, respectively, appear in Fig. 1, where the density of the secondary carriers considerably exceeds that ascribed to the dark current density. The densities of the secondary carriers do not coincide within the "tail" components of these secondary electrons and

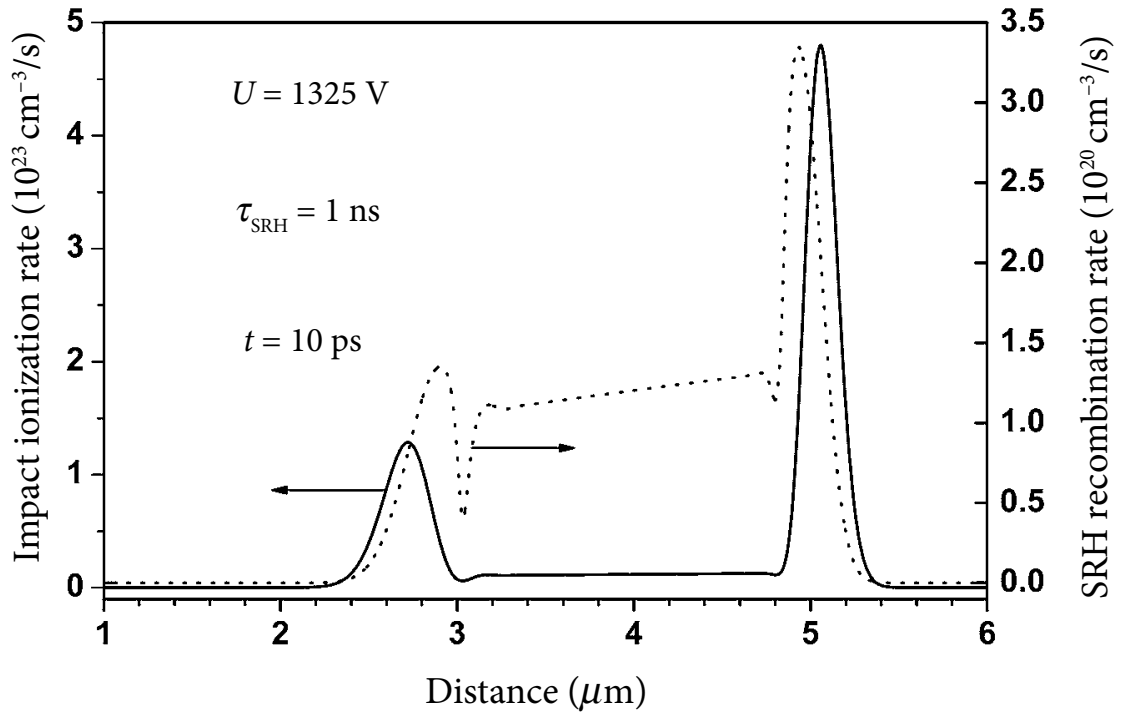

Fig. 2. Profiles of the impact ionization and recombination rate distribution simulated for a time instant of $t=10 \mathrm{ps}$. 


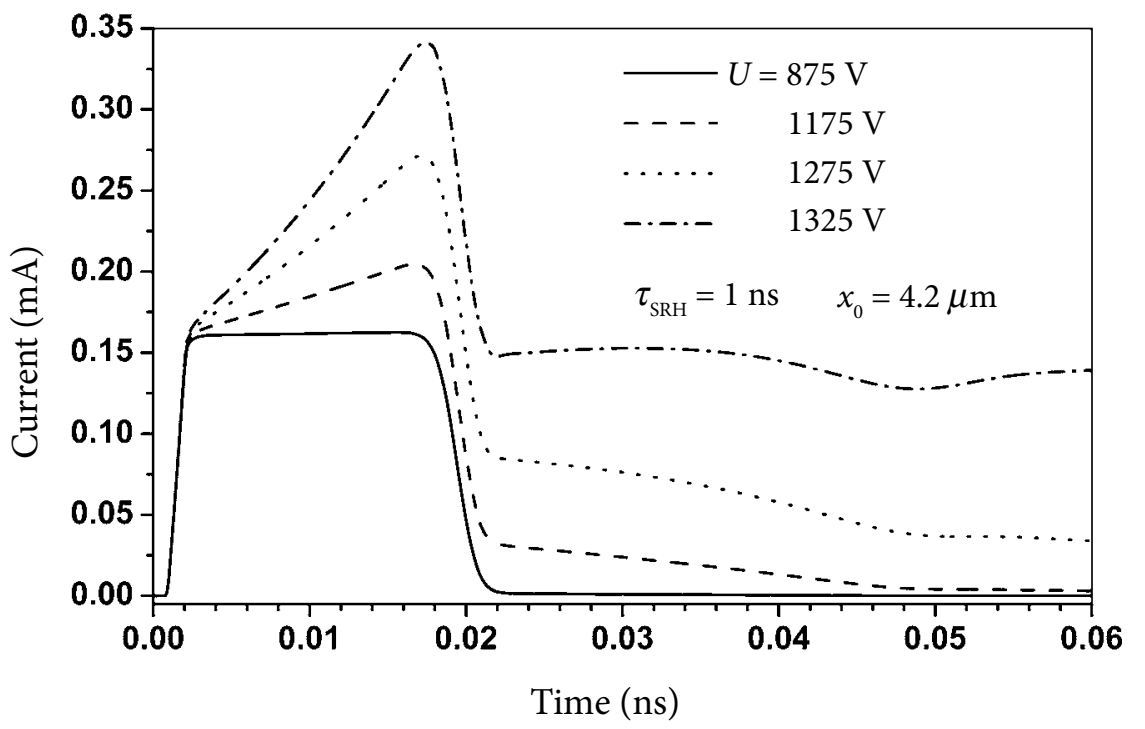

Fig. 3. Evolution of the $p-i-n$ diode current transients while varying the applied DC voltage, at the fixed parameters of the excess-carrier domain injection. holes because the values of the hole ionization coefficient significantly surpass those coefficients for electrons. These secondary carriers generate the ternary carriers leading to the avalanche process, evolved from the primary carrier drift. As a result, the difference between the electron and hole densities within the corresponding packets increases with time (Fig. 1). For instance, all the primary carriers and part of the secondary ones reach the high doping regions at the moment of $t=24 \mathrm{ps}$. Instants of the arrival of the carrier packets to the high doping regions coincide very well with the fast diode current fall between $t=20 \mathrm{ps}$ and $t=24 \mathrm{ps}$. Residual secondary, ternary and other carriers lead to the considerably lower rates of the impact ionization, and the current density relaxes to a very low value of the dark current.

\subsection{Evolution of current transients}

Evolution of the $p-i-n$ diode current transients has been investigated using a linear mode, when the diode voltage is lower than the static breakdown voltage, and an excess carrier domain of a rather low density is injected. The avalanche mode of diode operation evolves with an increase of the applied DC voltage. The evolution of the diode current transients with the voltage $U$, applied to the diode, is depicted in Fig. 3. At $U=875 \mathrm{~V}$, the impact ionization rate is negligible and the diode current pulse is almost rectangular. The pure bipolar drift is then held, as the electron and hole packets reach synchronously the electrodes due to the assumed initial injection position of the $x_{0}=4.2 \mu \mathrm{m}$. The rise time within the transient is in line with the optical excitation pulse duration of 2 ps. The pulse duration within the transient vertex represents the carrier bipolar-drift time. Duration of the current fall component within the transient is longer than the rise time due to carrier diffusion. Under an increase of the applied DC voltage to the values that are sufficient for the impact ionization, the current within the transient vertex increases almost linearly with time. The overall current increases with $U$ as well. The current fall-time, in the case of the considerable impact ionization, consists of two components: the fast component ascribed to the drift of electron and hole packets entering the $\mathrm{N}^{++}$and $\mathrm{P}^{++}$ regions, and the slow rear component, its duration being determined by the competing processes of the excess carrier generation, due to the impact ionization, and their recombination. Estimations of the recombination rates showed that the SRH recombination prevailed over the rates of the $\mathrm{Au}$ ger and radiative recombination by several orders of magnitude. Therefore, only the SRH recombination has been taken into further consideration of the recombination role.

A bipolarity of drift no longer holds (when the primary excess carriers, induced by impact ionization, leave the intrinsic material layer) because the secondary electrons and holes, generated by the impact ionization, occupy completely the intrinsic material layer, and carrier drift time 
is different due to the different saturation velocity for electrons and holes. A dimple appears within the current transient at an instant of $t=48 \mathrm{ps}$, indicating the moment when the secondary electrons reach the electrode region. In the later stages of the transients, the current relaxes to a small value of the dark current, for the considered DC voltage and injected carrier density range. The charge collected on the electrodes is equal to the area (integral) under the current curve of the diode transient response. The comparison of the transients simulated for $U=875 \mathrm{~V}$ and $U=1325 \mathrm{~V}$ shows that the collected charge for the case of the intensive impact-ionization process is many times larger than that below the threshold of the avalanche one.

\subsection{Impact of recombination}

Carrier lifetimes in heavily irradiated particle detectors may vary considerably due to the deep traps attributed to the radiation defects. A significant decrease of carrier lifetime with irradiation fluence affects detector signals, especially within the rear stages of the response pulses (Fig. 4).

Even for rather short optical injection pulses of 2 ps duration, the role of carrier recombination processes cannot be neglected. However, it can be balanced by the internal gain obtained at elevated external DC voltages, applied to a detector. Assuming a short carrier lifetime of $\tau_{\mathrm{SRH}}=10 \mathrm{ps,}$ the impact-ionization and consequent carrier generation rate (within drifting packets) exceeds the recombination rate by a factor of 10 . As a result, the detector current within the vertex of the response pulse decreases only by $13 \%$, when comparing with the situation of rather long carrier lifetime, $\tau_{\mathrm{SRH}}=1 \mathrm{~ns}$ (Fig. 4).

The impact of recombination is most pronounced within the profiles of the carrier density (Fig. 5) ascribed to the residual carrier distribution. The latter density determines the efficiency of charge collection in the radiation detector (Fig. 5).

The charge collected on electrodes can be simply evaluated by integrating a transient in time (Fig. 4), where an area surrounded by the current curve and time axis estimates the collected charge. It can be deduced from Figs. 3 and 4 that this area decreases with shortening of the carrier lifetime. An enhancement of the applied voltage can be employed to restore the charge collection efficiency (CCE) of a detector. It can be deduced from Fig. 3 that even for short carrier lifetimes of $10 \mathrm{ps,}$ an enhancement of the applied DC voltage from 875 to $1325 \mathrm{~V}$ leads to an increase of the charge collected on electrodes by a factor of 2 . The CCE parameter is the most important characteristic of a radiation sensor when these detectors are applied for spectroscopy of irradiations, not only as particle trackers.

\subsection{Profiling of detector transient responses}

Performance of the radiation sensors depends not only on the parameters of carrier generation and

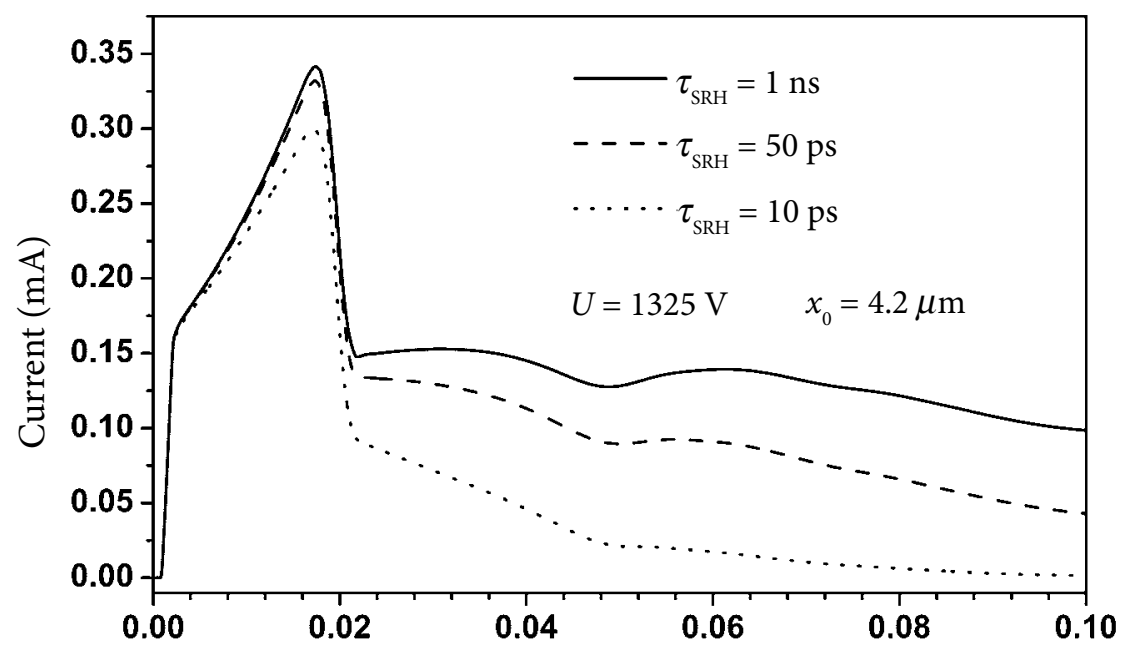

Time (ns)
Fig. 4. GaN detector current transients simulated by discretely varying the values of carrier lifetime in the case of the pulsed (of 2 ps duration) optical injection, located at $x_{0}=4.2 \mu \mathrm{m}$ within a diode inter-electrode gap, and at fixed 1325 V DC voltage. 


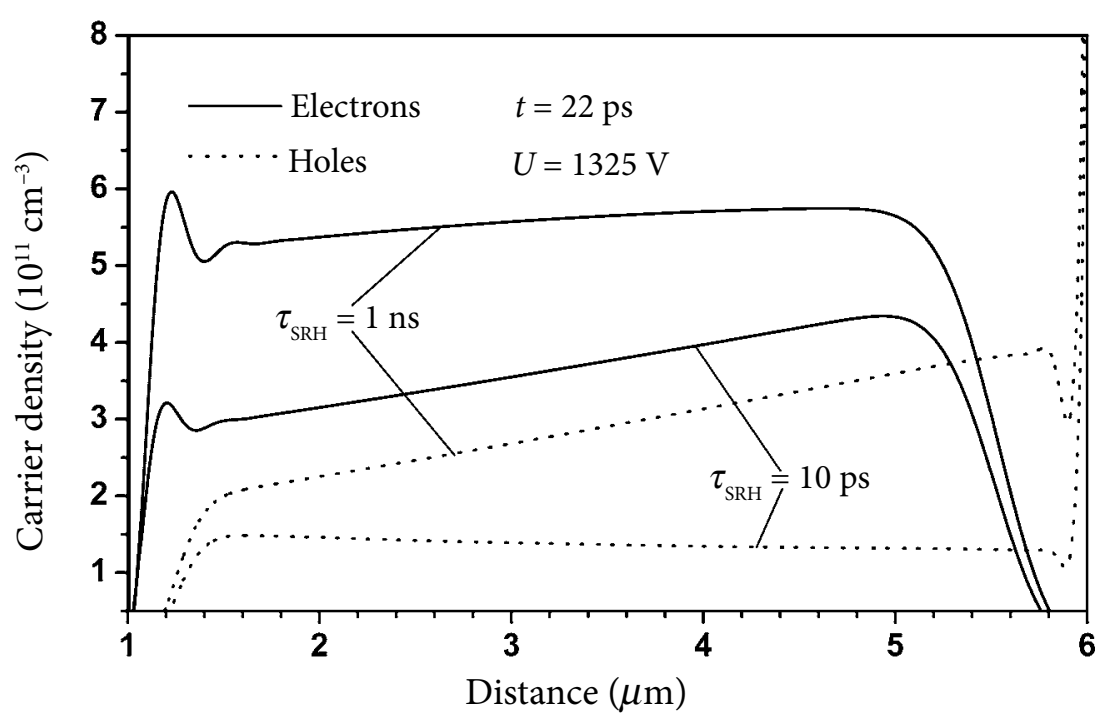

Fig. 5. The simulated profiles of the carrier density distribution within an active layer of the diode at an instant of 22 ps for different values of carrier lifetime. recombination in the material, but also on the energy and location of the incident ionizing radiation. A single high energy particle may cross the diode active layer at different locations, or rather wide beams of ionizing radiations excite a fixed area and depth of a sensor by generating secondary electron-hole pairs. In the case of local injection of the secondary carrier pairs, the drift time of electron and hole packets is different. As a result, the shape of the current pulse depends on the location $x_{0}$ of the injected excess carrier domain. This is illustrated in Fig. 6, where the simulated transients represent three injection situations: on the left side, in the middle, and on the right side of an active layer of the detector.
The shape of the current pulse changes drastically by varying the $x_{0}$. For the case $\left(x_{0}=1.05 \mu \mathrm{m}\right)$ when carrier pairs are injected close to the electrode that collects electrons, the hole packet drift prevails in the formation of the current transient. The current is mainly governed by the electron packet drift if the carrier pair domain is located $\left(x_{0}=5.95 \mu \mathrm{m}\right)$ nearby the electrode collecting holes. There changes of the instant values of the current and difference of pulse durations can be easily observed. A similar shape for these two cases could be implied where the ascending with time current indicates a gain obtained due to the avalanche processes. Nevertheless, the values of the hole current are several times larger than those for electrons, mainly due

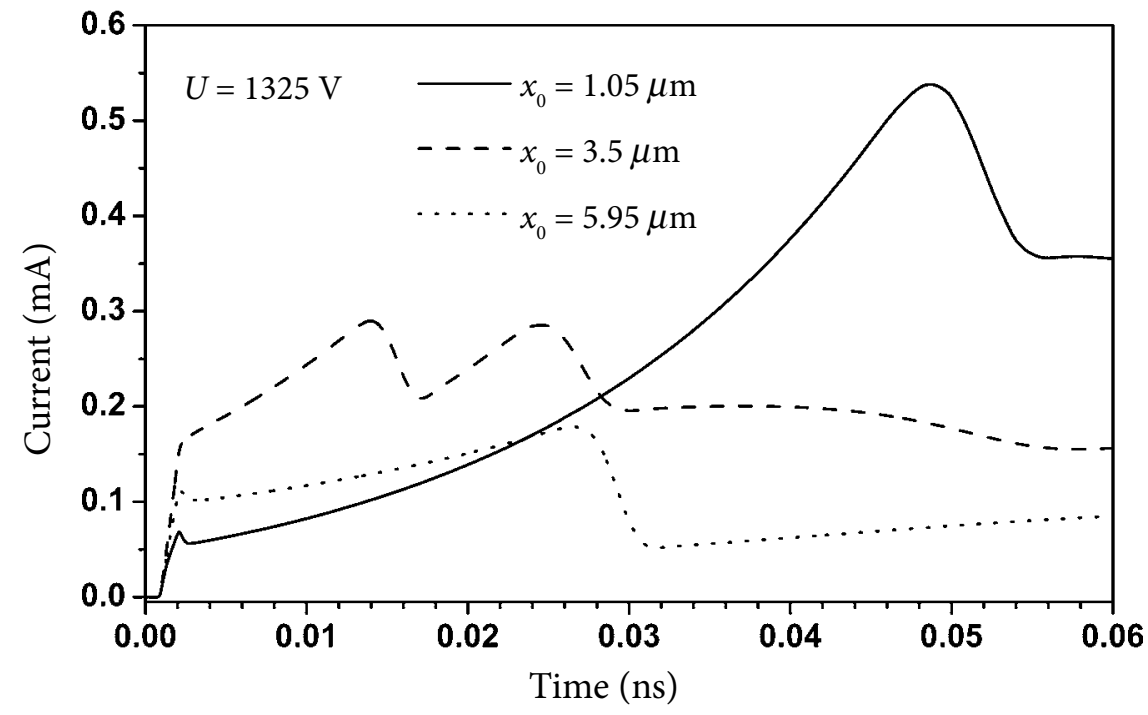

Fig. 6. Current transients simulated varying the initial position $x_{0}$ of the local carrier pair injection by an optical pulse of 2 ps duration at a fixed value of the applied DC voltage of $1325 \mathrm{~V}$. 
to the larger coefficient of the impact ionization for holes. However, the duration of the hole current pulse is 1.8 times longer than the electron pulse (i.e. $v_{\mathrm{ns}} / v_{\mathrm{ps}}=1.8$ ). For the third considered $\left(x_{0}=3.5 \mu \mathrm{m}\right)$ situation, the electron and hole packets cover nearly the same drift distance of $2.5 \mu \mathrm{m}$. However, a drift of the hole and electron sheets happens with different saturation velocities. Then, the current acquires a double-peak shape (Fig. 6). The first peak within the transient corresponds to the electron packet arrival to the $\mathrm{N}^{++}$layer, while the second one indicates an instant of the hole packet arrival to the $\mathrm{P}^{++}$layer.

\subsection{Discussion}

An assumption of the invariable voltage on electrodes is convenient for analysis of the internal processes of carrier generation, recombination and transport, by excluding any influence of the external circuit, as considered above. However, the realistic measurement circuits contain, at least, a load resistor of $R_{\mathrm{L}}=50 \Omega$ connected in series with a DC voltage source. In the case of the short time constant of $R_{\mathrm{L}} C_{\mathrm{d}}=7.4 \mathrm{ps}$, attributed to the charging processes within the external circuit, significant delays of the current rise-time and fall-time components can appear within the formation of detector current transients.

Variations of the current transients are illustrated in Fig. 月, as have been simulated for the GaN detector connected in series with the DC voltage source and the load resistor of $R_{\mathrm{L}}=50 \Omega$, by vary- ing the fixed values of the applied DC voltage. It can be deduced from Fig. 7 that the connection of the load resistor smooths the transients, by excluding clear dimples in current variations (observed in Figs. 3, 4), when comparing the transients of Fig. 7 with those depicted in Figs. 3 and 4 . Nevertheless, the delay (of $\gg 2 \mathrm{ps}$ ) of the fast current rise-time appears. The shape of the drift current increase with running time is close to the linear law or approaches the $\left(1-\exp \left(-t / R_{\mathrm{L}} C_{\mathrm{d}}\right)\right)$ form, as can be deduced from Fig. ㄱ. The smoothing of current changes within the transient (Fig. 7), determined by the load resistor, also leads to a decrease (by $21 \%)$ of the peak current value relative to that simulated without the load resistor (Figs. 3, 4). The rear stage within the transients, illustrated in Fig. 7, is also delayed, and no fast fall (resembling a step) of the current appears, in contrast to that observed in Figs. 3 and 4 for $t>20$ ps. However, smoothing of the dimples within the current transients, simulated for the elevated $(1175 \mathrm{~V})$ applied voltages, is not complete. This implies that these subtle current variations depend on the applied voltage and the injected/ionization induced carrier density. The current variations decrease with reduction of the values of DC voltage and carrier density.

Such current non-monotonicity effects do not appear when changes of the displacement induced charges on electrodes are taken into consideration [36] together with charges created by a voltage source. In other words, the changes of barrier capacitance due to injected and drifting

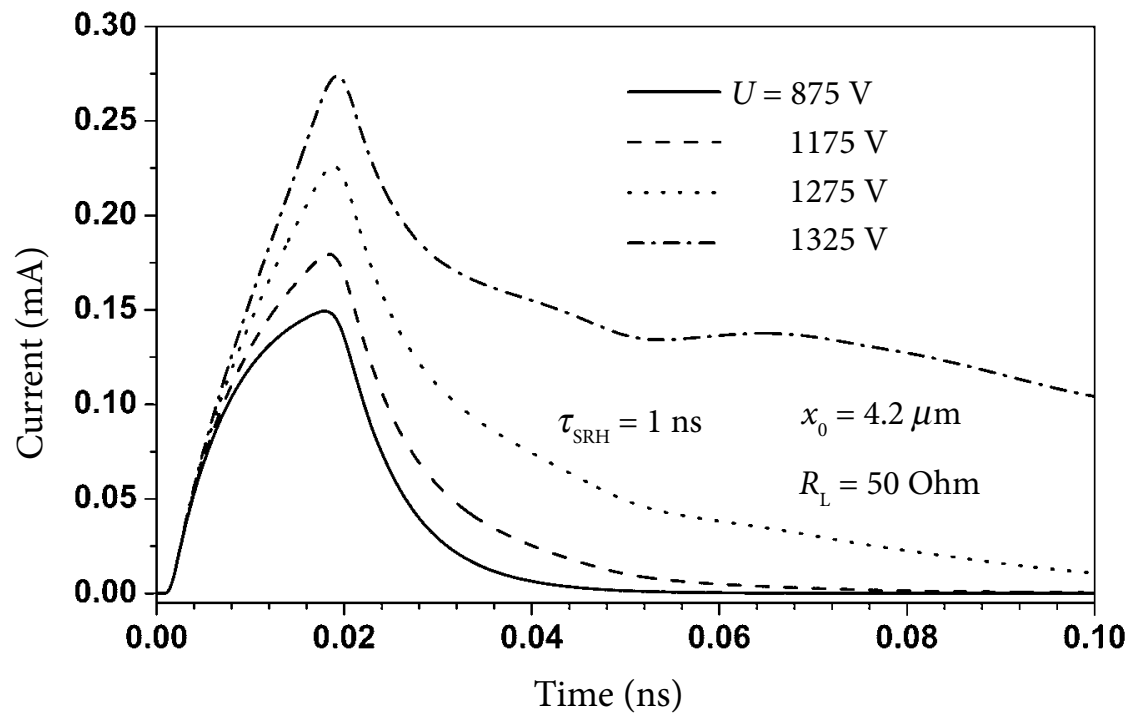

Fig. 7. Variations of the current transients simulated for the GaN detector connected in series with a DC voltage source and a load resistor of $R_{\mathrm{L}}=50 \Omega$, by varying the fixed values of applied DC voltage. 
charges create a feedback loop which modifies the acting electric field. The latter feedback effects are ignored within estimations of $R_{\mathrm{L}} C_{\mathrm{d}}(t)$ and the drift-diffusion model. Nevertheless, simulations of the evolution of the detector transient response by employing a drift-diffusion approach (model) reproduce properly the qualitative modifications of the main features of a detector with an internal gain. As a merit of TCAD simulations, a possibility to rapidly model the characteristics of the definite device structures is evident. These simulations are rather efficient when a degradation of the carrier lifetime and CCE parameters appears in $\mathrm{GaN}$ sensors 37, and a compensation of the charge loss, implemented by an internal gain, should be carefully adjusted. This procedure can be implemented by calibration of the simulated and measured sensor transients and by variation of the external voltage values, respectively.

\section{Summary}

An evolution of the transient characteristics of the GaN $p$ - $i-n$ diodes, operating in the avalanche mode and acting as particle sensors, has been simulated by using the Synopsys TCAD Sentaurus software package and the drift-diffusion approach. Profiling of the charge generation, recombination and drift-diffusion processes has been performed over a nanosecond time-scale with a precision of a few picoseconds and emulated through the photo-excitation of an excess carrier domain at different locations of the active volume of a diode. Fast and slow components within the current transient have been analysed based on consideration of the carrier spatial distribution of the avalanche process at different instants. It has been shown that the simulated evolution of the detector transient responses by employing the drift-diffusion approach reproduces properly the qualitative modifications of the main features of a detector with an internal gain, realized by the induction of avalanche processes governed by the applied external voltage.

\section{Acknowledgements}

This study was partially supported by the Lithuanian Research Council under the Grant Agreement LAT 01/2016.

\section{References}

[1] Y.-A. Chen, C.-H. Kuo, L.-C. Chang, and J.-P. Wu, Pulsed growth epitaxial method of GaN-based light-emitting diodes on patterned $\mathrm{SiO}_{2}$ AlN/Sapphire template, IEEE J. Quantum Electron. 50(10), 854-859 (2014).

[2] C.H. Kuo, Y.A. Chen, J.P. Wu, and L.C. Chang, Efficiency improvement of near-ultraviolet nitride-based light-emitting-diode prepared on GaN nano-rod arrays by metalorganic chemical vapor deposition, IEEE J. Quantum Electron. 50(3), 129-131 (2014).

[3] T. Frost, A. Banerjee, K. Sun, S.L. Chuang, and P. Bhattacharya, InGaN/GaN quantum dot red $(\lambda=630 \mathrm{~nm})$ laser, IEEE J. Quantum Electron. 49(11), 923-931 (2013).

[4] M.M. Satter, Z. Lochner, T.-T. Kao, Y.-S. Liu, X.-H. Li, S.-C. Shen, R.D. Dupuis, and P.D. Yoder, AlGaN-based vertical injection laser diodes using inverse tapered $\mathrm{p}$-waveguide for efficient hole transport, IEEE J. Quantum Electron. 50(3), 166-173 (2014).

[5] S.-C. Shen, Y. Zhang, D. Yoo, J.-B. Limb, J.-H. Ryou, P.D. Yoder, and R.D. Dupuis, Performance of deep ultraviolet GaN avalanche photodiodes grown by MOCVD, IEEE Photon. Technol. Lett. 19(21), 1744-1746 (2007).

[6] X. Wang, W. Hu, M. Pan, L. Hou, W. Xie, J. Xu, X. Li, X. Chen, and W. Lu, Study of gain and photoresponse characteristics for back-illuminated separate absorption and multiplication GaN avalanche photodiodes, J. Appl. Phys. 115(1), 013103-1-8 (2014).

[7] L.-Y. Su, F. Lee, and J.J. Huang, Enhancementmode GaN-based high-electron mobility transistors on the Si substrate with a $p$-type $\mathrm{GaN}$ cap layer, IEEE Trans. Electron Devices 61(2), 460-465 (2014).

[8] T.J. Anderson, A.D. Koehler, J.D. Greenlee, B.D. Weaver, M.A. Mastro, J.K. Hite, C.R. Eddy, Jr., F.J. Kub, and K.D. Hobart, Substratedependent effects on the response of AlGaN/ GaN HEMTs to $2-\mathrm{MeV}$ proton irradiation, IEEE Electron Device Lett. 35(8), 826-828 (2014).

[9] S.J. Pearton, B.S. Kang, S. Kim, F. Ren, B.P. Gila, C.R. Abernathy, J. Lin, and S.N.G. Chu, GaN- 
based diodes and transistors for chemical, gas, biological and pressure sensing, J. Phys. Condens. Matter 16(29), R961-R994 (2004).

[10]F. Calle, J. Pedros, T. Palacios, and J. Grajal, Nitride-based surface acoustic wave devices and applications, Phys. Stat. Sol. C 2(3), 976-983 (2005).

[11]D. Ciplys, M.S. Shur, N. Pala, A. Sereika, R. Rimeika, R. Gaska, and Q. Fareed, Ultravioletsensitive AlGaN-based surface acoustic wave devices, in: Proceedings of IEEE Sensors 2004 (IEEE, 2004) pp. 1345-1348.

[12]J. Vaitkus, W. Cunninghamb, E. Gaubas, M. Rahmanb, S. Sakai, K.M. Smith, and T. Wang, Semi-insulating GaN and its evaluation for $\alpha$ particle detection, Nucl. Instrum. Methods Phys. Res. A 509(1-3), 60-64 (2003).

[13]J. Vaitkus, E. Gaubas, T. Shirahama, S. Sakai, T. Wang, K.M. Smith, and W. Cunningham, Space charge effects, carrier capture transient behaviour and $\alpha$ particle detection in semi-insulating $\mathrm{GaN}$, Nucl. Instrum. Methods Phys. Res. A 514(1-3), 141-145 (2003).

[14]J. Grant, R. Bates, W. Cunningham, A. Blue, J. Melone, F. McEwan, J. Vaitkus, E. Gaubas, and $\mathrm{V}$. O'Shea, $\mathrm{GaN}$ as a radiation hard particle detector, Nucl. Instrum. Methods Phys. Res. A 576(1), 60-65 (2007).

[15]E. Gaubas, J. Vaitkus, K. Kazlauskas, A.Žukauskas, J. Grant, R. Bates, V. O'Shea, A. Strittmatter, D. Bimberg, and P. Gibart, Recombination characteristics of the proton and neutron irradiated semi-insulating GaN structures, Nucl. Instrum. Methods Phys. Res. A 83(1), 181-184 (2007).

[16]P. Mulligan, J. Wang, and L. Cao, Evaluation of freestanding $\mathrm{GaN}$ as an alpha and neutron detector, Nucl. Instrum. Methods Phys. Res. A 719(1), 13-16 (2013).

[17]J. Wang, P.L. Mulligan, and L.R. Cao, Transient current analysis of a $\mathrm{GaN}$ radiation detector by TCAD, Nucl. Instrum. Methods Phys. Res. A 761(1), 7-12 (2014).

[18]G. Wang, K. Fu, C. Yao, D. Su, G. Zhang, J. Wang, and M. Lu, GaN-based PIN alpha particle detectors, Nucl. Instrum. Methods Phys. Res. A 663(1), 10-13 (2012).
[19]E. Gaubas, T. Ceponis, A. Jasiunas, V. Kovalevskij, D. Meskauskaite, J. Pavlov, V. Remeikis, A. Tekorius, and J. Vaitkus, Correlative analysis of the in situ changes of carrier decay and proton induced photoluminescence characteristics in chemical vapor deposition grown GaN, Appl. Phys. Lett. 104(6), 062104-1-4 (2014).

[20]M. Moll, Radiation tolerant semiconductor sensors for tracking detectors, Nucl. Instrum. Methods Phys. Res. A 565(1), 202-211 (2006).

[21]S. Choi, H.J. Kim, Y. Zhang, X. Bai, D. Yoo, J. Limb, J.-H. Ryou, S.-C. Shen, P.D. Yoder, and R.D. Dupuis, Geiger-mode operation of $\mathrm{GaN}$ avalanche photodiodes grown on GaN substrates, IEEE Photon. Technol. Lett. 21(20), 1526-1528 (2009).

[22]F. Xie, H. Lu, D.J. Chen, X.Q. Xiu, H. Zhao, R. Zhang, and Y.D. Zheng, Metal-semiconductor-metal ultraviolet avalanche photodiodes fabricated on bulk GaN substrate, IEEE Electron Device Lett. 32(9), 1260-1262 (2011).

[23]S. Verghese, K.A. McIntosh, R.J. Molnar, L.J. Mahoney, R.L. Aggarwal, M.W. Geis, K.M. Molvar, E.K. Duerr, and I. Melngailis, GaN avalanche photodiodes operating in linear-gain mode and Geiger mode, IEEE Trans. Electron Devices 48(3), 502-511 (2001).

[24]M.J. Hsu, H. Finkelstein, and S.C. Esener, A CMOS STI-bound single-photon avalanche diode with 27-ps timing resolution and a reduced diffusion tail, IEEE Electron Device Lett. 30(6), 641-643 (2009).

[25]J.S. Ng, C.H. Tan, B.K. Ng, P.J. Hambleton, J.P.R. David, G.J. Rees, A.H. You, and D.S. Ong, Effect of dead space on avalanche speed [APDs], IEEE Trans. Electron Devices 49(4), 544-549 (2002).

[26]C. Groves, C.H. Tan, J.P.R. David, G.J. Rees, and M.M. Hayat, Exponential time response in analogue and Geiger mode avalanche photodiodes, IEEE Trans. Electron Devices 52(7), 1527-1534 (2005).

[27]M.M. Hayat, O.-H. Kwon, Y. Pan, P. Sotirelis, J.C. Campbell, B.E.A. Saleh, and M.C. Teich, Gain-bandwidth characteristics of thin avalanche photodiodes, IEEE Trans. Electron Devices 49(5), 770-781 (2002). 
[28]M. Ren, Y. Liang, W. Sun, G. Wu, J.C. Campbell, and $\mathrm{H}$. Zeng, Timing response of sinusoidal-gated Geiger mode InGaAs/InP APD, IEEE Photonics Technol. Lett. 26(17), 1762-1765 (2014).

[29]Y.G. Xiao and M.J. Deen, Temperature dependent studies of InP/InGaAs avalanche photodiodes based on time domain modeling, IEEE Trans. Electron Devices 48(4), 661-670 (2001).

[30]M.M. Hayat and G. Dong, A new approach for computing the bandwidth statistics of avalanche photodiodes, IEEE Trans. Electron Devices 47(6), 1273-1279 (2000).

[31]D. Zhou, F. Liu, H. Lu, D. Chen, F. Ren, R. Zhang, and Y. Zheng, High-temperature single photon detection performance of $4 \mathrm{H}-\mathrm{SiC}$ avalanche photodiodes, IEEE Photonics Technol. Lett. 26(11), 1136-1138 (2014).

[32]A. Dalla Mora, A. Tosi, S. Tisa, and F. Zappa, Single-photon avalanche diode model for circuit simulations, IEEE Photonics Technol. Lett. 19(23), 1922-1924 (2007).
[33] K. Bløtekjær, Transport equations for electrons in two-valley semiconductors, IEEE Trans. Electron Devices 17(1), 38-47 (1970).

[34]R. van Overstraeten and H. de Man, Measurement of the ionization rates in diffused silicon $p-n$ junctions, Solid State Electron. 13(5), 583-608 (1970).

[35]M. Farahmand, C. Garetto, E. Bellotti, K.F. Brennan, M. Goano, E. Ghillino, G. Ghione, J.D. Albrecht, and P.P. Ruden, Monte Carlo simulation of electron transport in the III-nitride wurtzite phase materials system: binaries and ternaries, IEEE Trans. Electron Devices 48(3), 535-542 (2001).

[36]E. Gaubas, T. Ceponis, V. Kalesinskas, J. Pavlov, and J. Vysniauskas, Simulations of operation dynamics of different type GaN particle sensors, Sensors 15(3), 5429-5473 (2015).

[37]E. Gaubas, T. Ceponis, L. Deveikis, D. Meskauskaite, S. Miasojedovas, J. Mickevicius, J. Pavlov, K. Pukas, J. Vaitkus, M. Velicka, M. Zajac, and R. Kucharski, Study of neutron irradiated structures of ammonothermal GaN, J. Phys. D 50, 135102 (2017).

\title{
GaN GRIŪTINIO $p$ - $i-n$ STRUKTŪROS DALELIŲ DETEKTORIAUS SU VIDINIU STIPRINIMU DINAMINIŲ CHARAKTERISTIKŲ MODELIAVIMAS
}

\author{
J. Vyšniauskas ${ }^{\text {a }}$, E. Gaubas ${ }^{\text {b }}$ \\ a Vilniaus universiteto Taikomosios elektrodinamikos ir telekomunikaciju institutas, Vilnius, Lietuva \\ ${ }^{\mathrm{b}}$ Vilniaus universiteto Fotonikos ir nanotechnologiju institutas, Vilnius, Lietuva
}

\section{Santrauka}

Galio nitrido $p-i-n$ griūtinio diodo dinaminès charakteristikos buvo sumodeliuotos, pasitelkiant dreifinidifuzinị modelị iš Synopsys TCAD Sentaurus programų paketo. Tokių spinduliuotès jutiklių srovès signalų kitimų profiliavimas ígyvendintas emuliuojant spinduliuotès poveikị antrinių krūvininkų porų injekcija ịvairiose diodo aktyviosios srities vietose, pasitelkiant optinio sužadinimo trumpais impulsais parametrus, artimus eksperimentinèms situacijoms. Parodyta, kad difuzijosdreifo artinys yra tinkamas GaN $p$-i- $n$ detektorių charakteristikų kaitos sumodeliavimui ir radiacinès jutikliu degradacijos kompensavimui, pasitelkiant valdomą išorine ịtampa griūtinị diodo režimą. Dèl krūvininkų dauginimosi vidinis stiprinimas užtikrina pakankamą krūvio surinkimą gana plonuose (5 mikrometrai) dalelių jutikliuose. 